Article

\title{
An Innovative and Cost-Advantage CAD Solution for Cubitus Varus Surgical Planning in Children
}

\author{
Leonardo Frizziero ${ }^{1, *}\left(\mathbb{D}\right.$, Gian Maria Santi ${ }^{1}\left(\mathbb{D}\right.$, Christian Leon-Cardenas ${ }^{1}$, Giampiero Donnici ${ }^{1}{ }^{1}$, \\ Alfredo Liverani ${ }^{1}{ }^{1}$, Francesca Napolitano ${ }^{1}$, Paola Papaleo ${ }^{1}$, Curzio Pagliari ${ }^{1}$, Diego Antonioli ${ }^{2}$, \\ Stefano Stallone ${ }^{2} \mathbb{D}$, Giovanni Luigi Di Gennaro ${ }^{2}$, Giovanni Trisolino ${ }^{2} \mathbb{C}$ and Paola Zarantonello ${ }^{2} \mathbb{C}$
}

1 Department of Industrial Engineering, Alma Mater Studiorum University of Bologna, 40136 Bologna, Italy; gianmaria.santi2@unibo.it (G.M.S.); christian.leon2@unibo.it (C.L.-C.); giampiero.donnici@unibo.it (G.D.); alfredo.liverani@unibo.it (A.L.); francesca.napolitan5@studio.unibo.it (F.N.); paola.papaleo2@studio.unibo.it (P.P.); cuzio.pagliari@studio.unibo.it (C.P.)

2 Paediatric Orthopaedics and Traumatology, IRCCS-Istituto Ortopedico Rizzoli (Rizzoli Ortopaedic Institute), 40136 Bologna, Italy; diego.antonioli@ior.it (D.A.); stefano.stallone@ior.it (S.S.); giovanniluigi.digennaro@ior.it (G.L.D.G.); giovanni.trisolino@ior.it (G.T.); paola.zarantonello@ior.it (P.Z.)

* Correspondence: leonardo.frizziero@unibo.it

check for updates

Citation: Frizziero, L.; Santi, G.M.; Leon-Cardenas, C.; Donnici, G.; Liverani, A.; Napolitano, F.; Papaleo, P.; Pagliari, C.; Antonioli, D.; Stallone, S.; et al. An Innovative and Cost-Advantage CAD Solution for Cubitus Varus Surgical Planning in Children. Appl. Sci. 2021, 11, 4057. https://doi.org/10.3390/app11094057

Academic Editor: Lapo Governi

Received: 23 March 2021

Accepted: 20 April 2021

Published: 29 April 2021

Publisher's Note: MDPI stays neutral with regard to jurisdictional claims in published maps and institutional affiliations.

Copyright: (c) 2021 by the authors. Licensee MDPI, Basel, Switzerland. This article is an open access article distributed under the terms and conditions of the Creative Commons Attribution (CC BY) license (https:// creativecommons.org/licenses/by/ $4.0 /)$.

\begin{abstract}
The study of CAD (computer aided design) modeling, design and manufacturing techniques has undergone a rapid growth over the past decades. In medicine, this development mainly concerned the dental and maxillofacial sectors. Significant progress has also been made in orthopedics with pre-operative CAD simulations, printing of bone models and production of patient-specific instruments. However, the traditional procedure that formulates the surgical plan based exclusively on two-dimensional images and interventions performed without the aid of specific instruments for the patient and is currently the most used surgical technique. The production of custom-made tools for the patient, in fact, is often expensive and its use is limited to a few hospitals. The purpose of this study is to show an innovative and cost-effective procedure aimed at prototyping a custom-made surgical guide for address the cubitus varus deformity on a pediatric patient. The cutting guides were obtained through an additive manufacturing process that starts from the 3D digital model of the patient's bone and allows to design specific models using Creo Parametric. The result is a tool that adheres perfectly to the patient's bone and guides the surgeon during the osteotomy procedure. The low cost of the methodology described makes it worth noticing by any health institution.
\end{abstract}

Keywords: cutting guides; preoperative simulation; CAD Modeling; 3D Printing; pediatric orthopedics; surgery and diagnostics

\section{Introduction}

In the last few decades, the development of techniques and materials has allowed great advances in various fields of technology; medicine, in particular orthopedics, is among the sectors that have benefited most from it. The term computer assisted orthopedic surgery (CAOS) synthetically denotes a large group of applications in the orthopedic field that use computers in order to make surgical procedures less invasive, more effective, safe and reliable [1-3].

The custom-made surgical guides are cutting tools made to measure for the patient. In the orthopedic field, they help the surgeon by facilitating osteotomy bone cutting in highly complex surgical interventions. To date, most surgical operations are performed freehand and their success is strongly correlated to the skill and experience of the surgeon. The use of surgical guides allows you to cut the bone in a very specific direction. In this way, the operation is completely constrained and therefore can be carried out easily even by less experienced surgeons. In addition, research conducted by Ballard et al. has shown that the use of surgical guides in orthopedics allows a reduction in intervention times and, 
consequently, a reduction in the necessary costs [4]. This research considers 21 orthopedic cases (Table 1, Figure 1, Reproduced with permission from Ballard, D. et al., Copyright publisher, 2020).

Table 1. Reduction of time in the operating room following the use of cutting guides. The negative values in the "Operative minutes saved" column denote minutes saved while positive values denote added time with the 3D printed construct.

\begin{tabular}{|c|c|c|c|c|}
\hline & Study & $\begin{array}{l}\text { Operative Minutes Saved in } \\
\text { Experimental Groups } \\
\text { Compared to Control Group }\end{array}$ & $\begin{array}{c}\text { Patients in } \\
\text { Experimental Group }\end{array}$ & Patients in Control Group \\
\hline 1 & Zhang et al. [5] & 78 & 11 & 11 \\
\hline 2 & Hsu et al. [6] & -12 & 42 & 29 \\
\hline 3 & Chareancholvanich et al. [7] & -5.1 & 40 & 40 \\
\hline 4 & Abane et al. [8] & -6.3 & 59 & 67 \\
\hline 5 & Barrack et al. [9] & -11 & 100 & 100 \\
\hline 6 & Barrett et al. [10] & -5.2 & 66 & 86 \\
\hline 7 & Boonen et al. [11] & -10 & 39 & 40 \\
\hline 8 & Boonen et al. [12] & -5 & 90 & 90 \\
\hline 9 & Ferrara et al. [13] & -22.3 & 15 & 15 \\
\hline 10 & Gan et al. [14] & -15 & 35 & 35 \\
\hline 11 & Hamilton et al. [15] & 4.3 & 26 & 26 \\
\hline 12 & Kassab and Pietrzak, [16] & -16.7 & 270 & 595 \\
\hline 13 & Kerens et al. [17] & 5 & 30 & 30 \\
\hline 14 & Nankivell et al. [18] & -4 & 40 & 45 \\
\hline 15 & Noble et al. [19] & -6.7 & 19 & 15 \\
\hline 16 & Nunley et al. [20] & -12.1 & 57 & 57 \\
\hline 17 & Pfitzner et al. [21] & -15.5 & 60 & 30 \\
\hline 18 & Pietsch et al. [22] & -12 & 40 & 40 \\
\hline 19 & Rathod et al. [23] & -18 & 15 & 14 \\
\hline 20 & Renson et al. [24] & -8.9 & 71 & 60 \\
\hline 21 & Roh et al. [25] & 12.8 & 50 & 50 \\
\hline & Mean (median) & $-12(-10)$ & $56(40)$ & $70(40)$ \\
\hline
\end{tabular}

3D printed surgical guides: all studies $(n=25)$

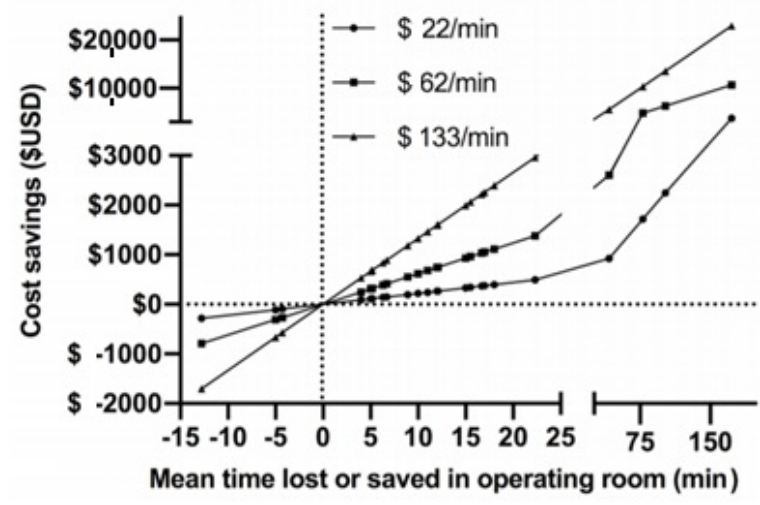

Figure 1. Cost-savings from operative room time. The study included 21 orthopedic cases and 4 maxillofacial cases $(n=25)$. 
The innovative methodology with the use of surgical guides provides for preoperative CAD planning aimed at identifying the cutting plans and, consequently, at verifying the positioning of the guide. Finally, the 3D printed bone model allowed to simulate the positioning of the guide before the actual surgery is performed.

\subsection{Cubitus Varus Syndrome}

Cubit varus is a deformation of the elbow caused by a deviation of the forearm inwards. This deformation can have a congenital or acquired origin. Among the main causes of acquired cubitus varus is the supracondylar fracture of the humerus. Cubitus varus following supracondylar humerus fracture in children consists of varus deformity, hyperextension and internal rotation of the distal humerus bone fragment [26-29].

The slight forms of cubit do not alter the functionality of the elbow and are mainly a problem of an aesthetic nature. Conversely, severe forms of cubitus varus can cause functional elbow disorders (Figure 2).

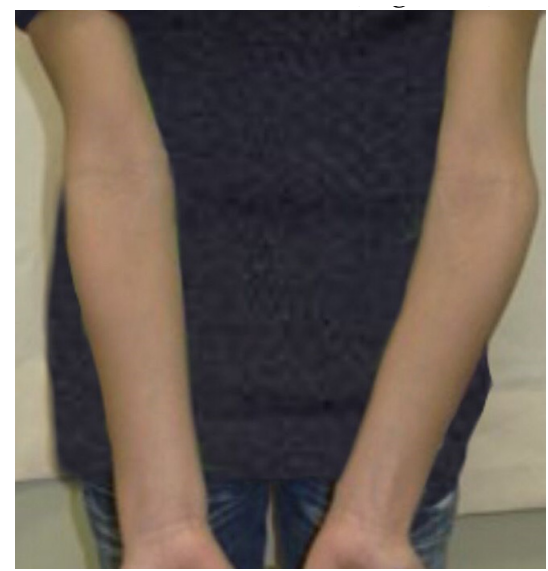

(a)

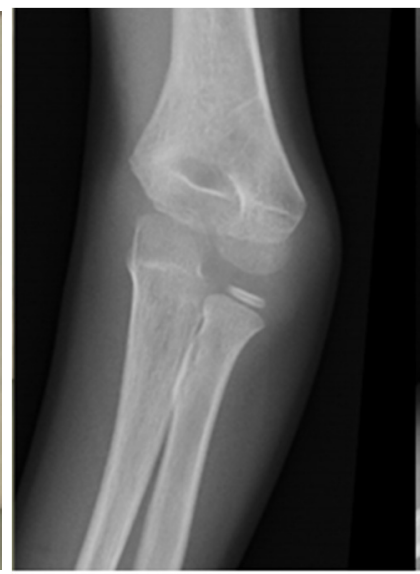

(b)

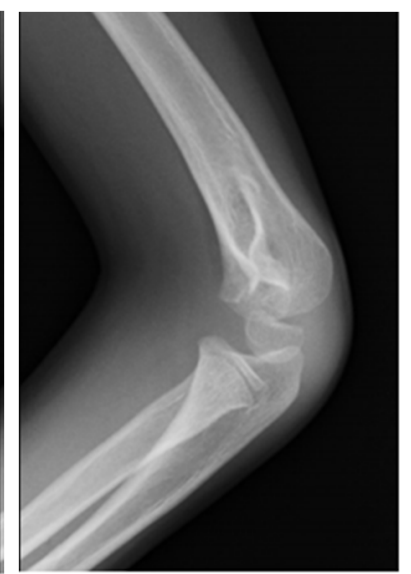

(c)

Figure 2. Deformity of the varus cubitus in the left elbow (a). The inclination angle is 15 varus (b) and 25 (c) respectively.

\subsection{Cutting Guides for Surgery}

Below are some representative examples of custom-made orthopedic surgical guides taken from the literature, analyzing their peculiar characteristics. All the surgical guides analyzed were made for pediatric patients suffering from cubitus varus deformity.

A study conducted by Tricot et al. [30] led to the fabrication of a real acrylic model of an osteotomy template [30]. A model of the patient's humerus was created by rapid prototyping using a 3D-plaster printing based on the CT scanner data. The guides were created by the contact of the prototypes with one unique possible position. The surgical guide made by Zhang et al. [31] was also made in acrylate resin and printed with the stereolithography rapid prototyping technique (SLA) (Figure 3a) [31]. Invented in the 1980s, it was the first 3D printing technology in the world and is still one of the most popular technologies on a professional level. Stereolithography uses a laser to polymerize the liquid resin into hardened plastic.

The template made by Murase et al. [28] was designed based on a preoperative three-dimensional computer simulation with use of commercially available software (Bone Viewer and Bone Simulator; Orthree, Osaka, Japan) and was produced as a plastic model with use of rapid prototyping technology and medical-grade resin. Two metal osteotomy slits and four metal sleeves are mounted on the template (Figure 3b) [28]. 


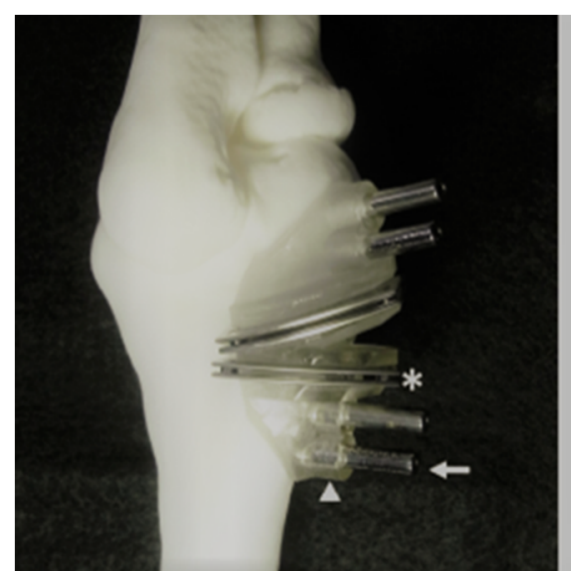

(a)

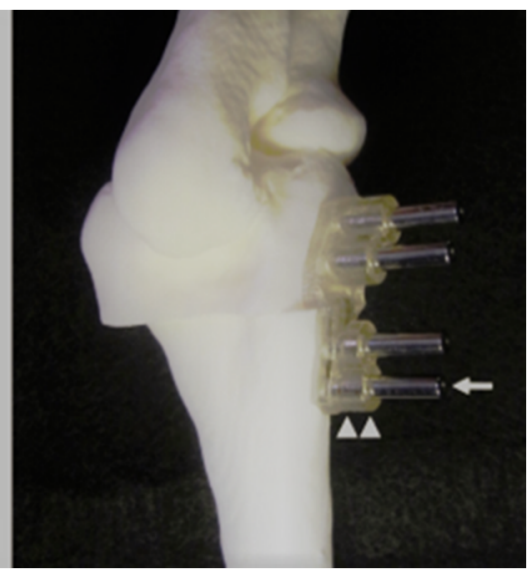

(b)

Figure 3. The osteotomy template made by Murase et al. [28] (2014): (a) two metal osteotomy slits and (b) four metal sleeves are mounted.

The surgical guides made by $\mathrm{Hu}$ et al. were printed using polylactic acid (PLA) (Figure 4a) [32,33]. The PLA guides are printed using thermoplastic material deposition technology (FDM-Fused Deposition Modelling or FFF-Fused filament fabrication), which is the most used method as it is economical, reproducible and versatile. FDM printers basically consist of a nozzle that heats up to $200{ }^{\circ} \mathrm{C}-250{ }^{\circ} \mathrm{C}$ depending on the material and extrudes a plastic filament depositing it layer by layer on a heated bed. This material has printing temperatures between 200 and $220^{\circ}$ and it is not toxic. However, its glass transition temperature of $55-65^{\circ} \mathrm{C}$ makes it deformable at high temperatures [33]. In fact, once the print is finished, the piece must undergo a sterilization process in order to be used in the operating room. There are several sterilization methods available in hospitals. The most common are sterilization in an autoclave, gas plasma and ethylene oxide (EtO). The sterilization in an autoclave is the most common method of sterilization because it is inexpensive and non-toxic. It involves temperatures between 121 and $134{ }^{\circ} \mathrm{C}$ under pressure. The higher temperatures used in the process could theoretically affect the structure of prints, especially those made from PLA with lower glass transition temperatures. Ethylene oxide is a gas frequently used for low temperature sterilization $\left(54{ }^{\circ} \mathrm{C}\right)$, but due to its high toxicity it requires cycles of up to $14 \mathrm{~h}$ mainly for washing with air. The gas plasma uses hydrogen peroxide and temperatures of $37-44{ }^{\circ} \mathrm{C}$. It represents one of the most advanced techniques for sterilization: it consists in the application of hydrogen peroxide in the gaseous state in the presence of a strong electric field. This brings the peroxide to the plasma state by stripping electrons and generating free radicals. The radicals have a high germicidal capacity and considerably damage cell membranes. However, bacterial growth was observed on cylinders printed in PLA using a 3D printer with a filling density of $12 \%$ and sterilized with hydrogen peroxide. Therefore, the use of plasma gas for the sterilization of PLA surgical guides is not recommended. Otherwise, in order to avoid the risk of contamination during the sterilization process, a filling density of $100 \%$ should be used when molding the surgical guides [34]. It follows that the use of PLA as a printing material for surgical guides is not particularly convenient.

The surgical guides made by Barbier et al. [35] were printed in biocompatible polyamide material by selective laser sintering (Figure 4b) [36]. PA12 (Poliammide 12, Nylon 12) is a polyamide synthetic fiber commonly used for 3D printing in the medical field. It is characterized by high thermal and mechanical resistance; therefore, it is suitable for producing functional prototypes. Selective Laser Sintering (SLS) is preferred as a material printing technique. It is an additive manufacturing technology that uses a high-powered laser to sinter small particles of polymer powder and transform them into a solid structure based on a 3D model [36-38]. Nylon can withstand high temperatures. The sterilization of the prototypes in an autoclave is therefore allowed. 


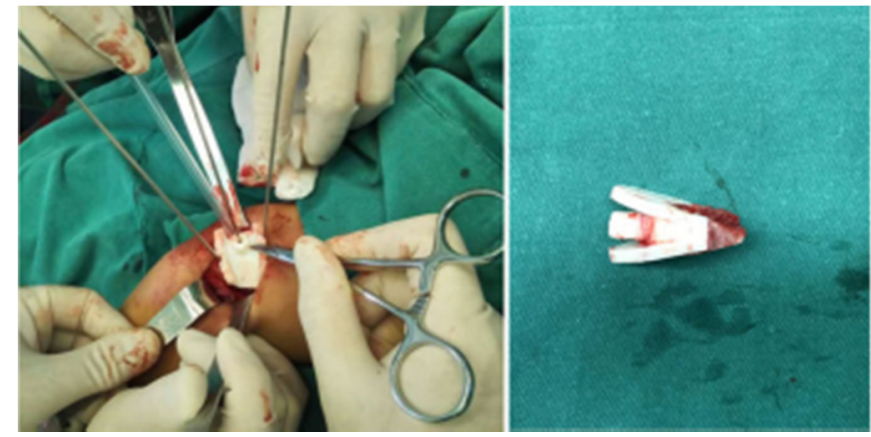

(a)

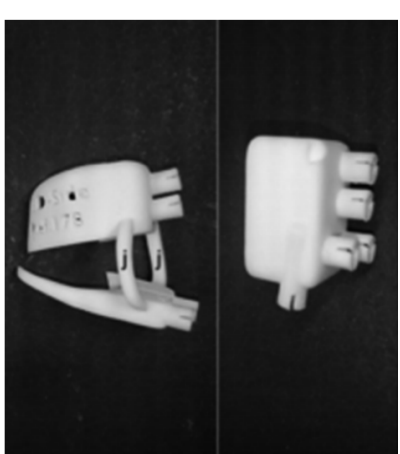

(b)

Figure 4. (a) Cutting guides printed in medical polylactic acid (PLA) material and (b) in polyamide biocompatible material.

Ultimately, the custom-made surgical guides made to date differ in design procedure, construction materials, printing technology and sterilization method. The most used programs for 3D simulation and mask design are not available for free use (Materialize Mimics, Bone Viewer and Bone Simulator). In recent years, the materials mainly used for printing the cutting guides are PLA and Nylon. PLA is widely used for its low cost and extreme printing simplicity. However, it is not suitable for use at high temperatures. An alternative is Nylon PA12, which shows the best thermal characteristics, but its production is complex because it is made with SLS technology.

The goal of this research is to design an innovative custom-made cutting guide that can gather the advantages that emerged from the study of the surgical guides made to date. The central focus of the entire work carried out is represented by the precious collaboration between the Department of Industrial Engineering (DIN) of the University of Bologna and the Rizzoli Orthopedic Institute (IOR) of Bologna, aimed at identifying useful engineering tools to be applied to medical field.

\section{Materials and Methods}

\subsection{Study Design and Clinical Case}

The case of a unilateral post-traumatic cubitus varus deformity is examined below. The pediatric patient in question has clinical varus in the left forearm of about $15-18^{\circ}$.

The therapy to be followed is exclusively surgical and consists of a corrective osteotomy with the removal of a bone wedge, followed by a period of physiotherapy.

In traditional orthopedic procedures, during the surgical operation it can be difficult to accurately check the angle of correction due to the reduced visibility of the intervention area. For this reason, the degree of correction often has to be adjusted several times during surgery and this can cause a prolongation of the operative phases with related complications and a high risk of incurring unsatisfactory clinical results. Accurate preoperative planning using the CAOS system, Software Systems for Structural Optimization, Springer, and the creation of patient-specific instruments (PSI) such as surgical guides are therefore necessary in order to achieve an accurate anatomical correction for cubitus varus deformity.

\subsection{Computer Aided Surgical Simulation}

The starting point is the generation of the 3D Digital Model of the bone from the tomographic images (CT). The software used were Invesalius (v. 3.1), MeshLab (v. 2016.12) and Meshmixer (v. 2017). Invesalius is an open-source software for reconstruction of computed tomography and magnetic resonance images. MeshLab and Meshmixer are graphic software used to correct any mesh irregularities [39-44]. The process from CT to $3 \mathrm{D}$ digital model is illustrated in Figure 5.

The surgery is planned using the $3 \mathrm{D}$ generated model. In this work, the parametric software used to perform the simulation is Creo Parametric (v.6), made by PTC, 121 Seaport 
Boulevard, Boston, MA, 02210. Parametric software is the ideal choice if you plan to make quick changes to the project, even during construction, as in the case of simulations.

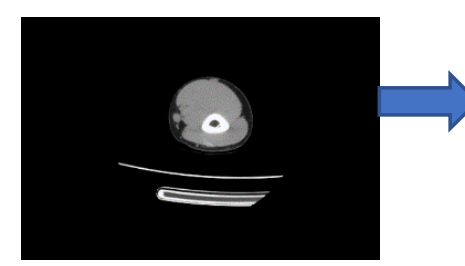

Tomographic images

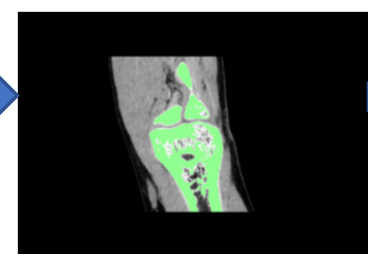

Setting the density range

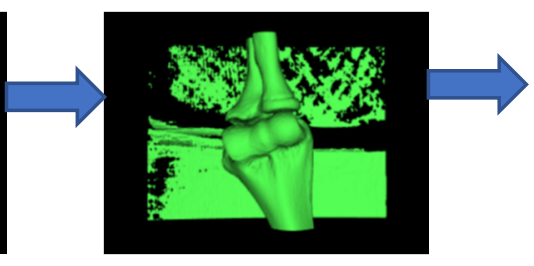

Mesh generation
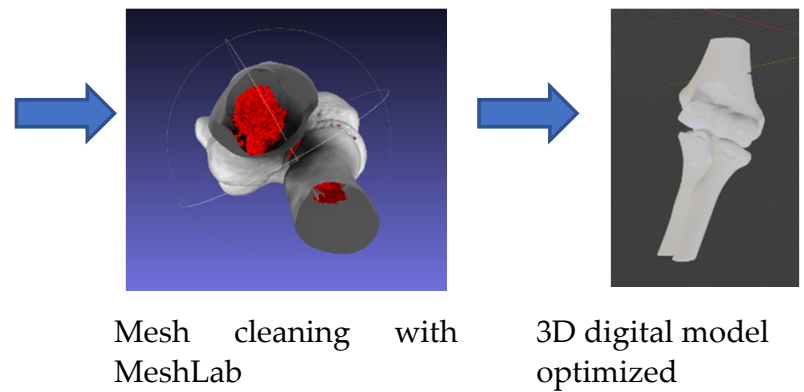

3D digital model optimized

Figure 5. From CT to 3D Digital Model.

Based on the theoretical guidelines provided by the doctors, the engineers simulated the interventions and the results that can be achieved during the operation. If these results do not meet the surgeons' expectations, it is possible to regenerate the model and proceed with the identification of the best solution to be achieved. Ultimately, the preview knowledge of the result of the operation gives rise to a relevant tool that favors the identification of the most suitable surgical strategy in relation to the case analyzed (Figure 6).

The simulation of corrective osteotomy also has the purpose of identifying the cutting planes to be used for the sizing of the surgical guide. In the case analyzed, it is considered that:

$\checkmark \quad$ The plane of the distal osteotomy, approximately parallel to the distal articular surface, is placed approximately $10 \mathrm{~mm}$ above the olecranon fossa;

$\checkmark \quad$ The proximal osteotomy plane forms an angle of $22^{\circ}$ with the distal osteotomy plane.

\subsection{Surgical Guide Planning}

Before proceeding with the CAD design of the cutting guide, it is necessary a comparison between engineers and surgeons in order to outline the guidelines to be followed for a correct configuration of the mask.

To this end, it was useful to print the 3D model of the bone on which the cut is to be made. This model can be printed in PLA since the print is not intended for use in the operating room and sterilization is not required.

Using small quantities of wax or plasticine it is possible to make a preliminary reproduction of the surgical guide. In this way, surgeons can communicate their ideas, highlighting the crucial points that need to pay particular attention when designing the cutting template (Figure 7).

During this phase, the choice of blades to be inserted in the surgical motor and of the pins to be used for fixing the guide is also made. In the case in question, blades were chosen with a cutting thickness of $1.04 \mathrm{~mm}$ and with an edge size of $17.2 \mathrm{~mm}$. The chosen pins have a diameter of $1.80 \mathrm{~mm}$.

The choice of the blades and pins to be used and the verification of the oscillatory motion performed by the blade when the drill is in operation, are fundamental for the choice of the dimensions and tolerances to be used in the design of the notches, necessary for the passage of the blades and holes, necessary for the passage of the pins. 


\section{SIMULATION PROCESS}
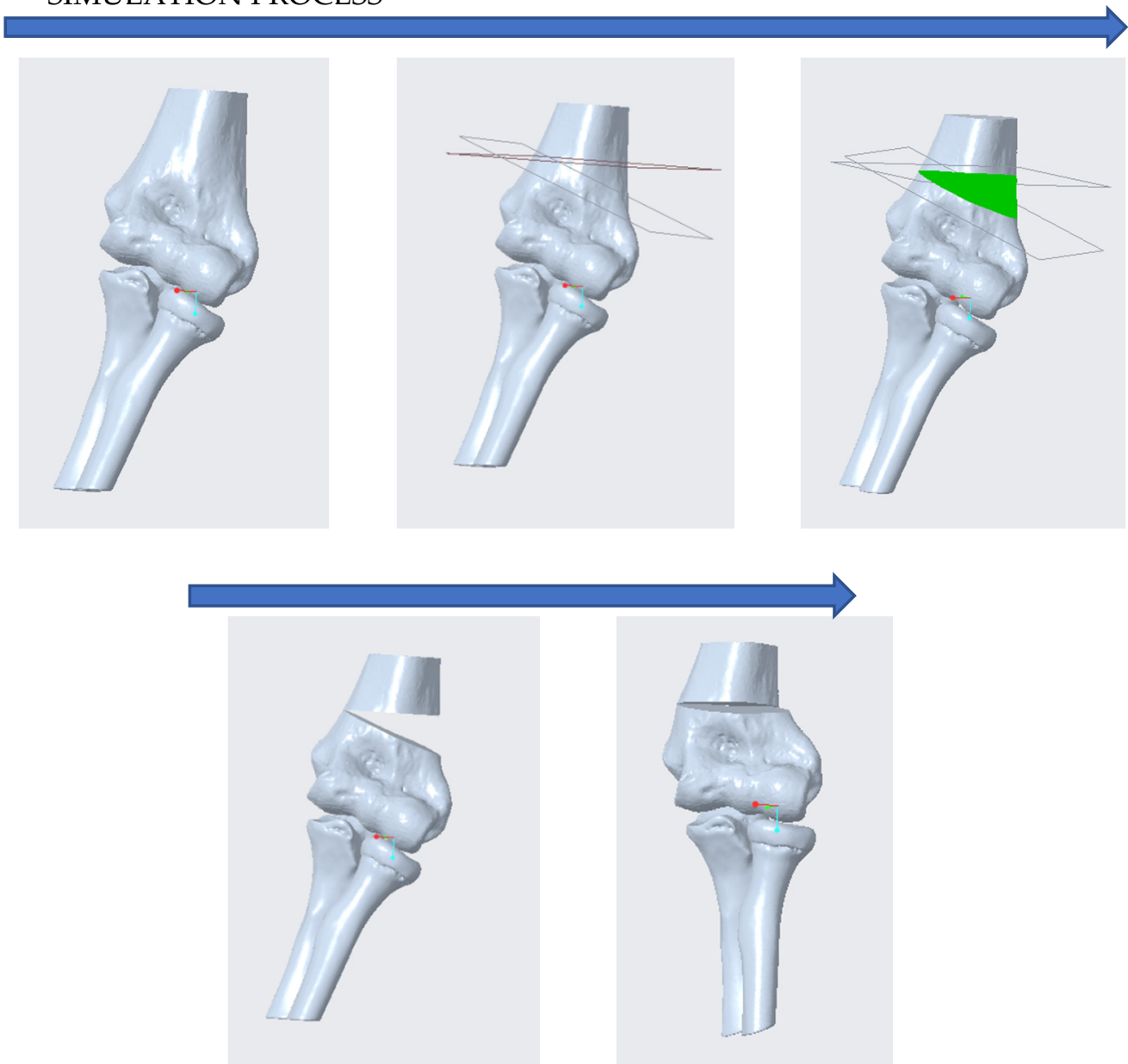

Figure 6. Computer Aided Surgical Simulation with Creo Parametric.

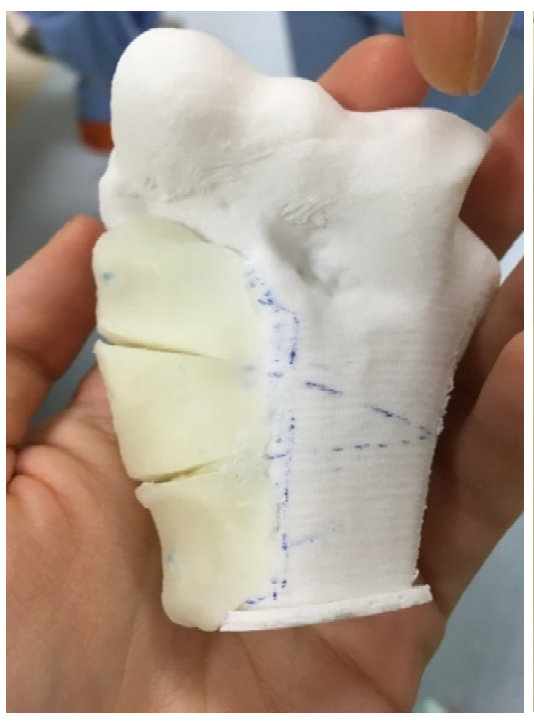

(a)

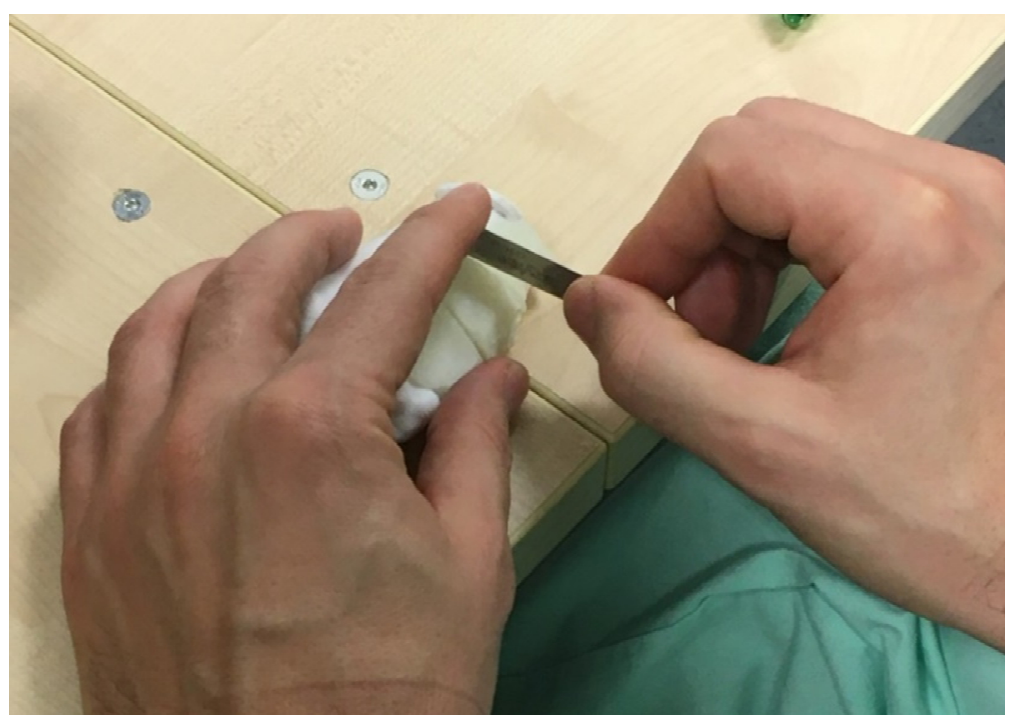

(b)

Figure 7. Surgical Guide Planning: (a) Preliminary reproduction of the surgical guide made with wax; (b) Choice of blades to be used during the operation and sizing of the notches. 


\subsection{CAD Design of the Surgical Guide}

The next step is to design the cut guide outlined, using the Creo Parametric CAD software (v6), made by PTC, 121 Seaport Boulevard, Boston, MA, 02210. The cutting guide must adhere perfectly to the surface of the bone. For this reason, its design traced the exact shape of the bone faithfully.

On the surgical guide, it is possible to generate the holes for the passage of the pins. A diameter of $2.10 \mathrm{~mm}$ was chosen for the holes. This measure was identified after several prints aimed at choosing the right tolerance margin.

The cutting planes found in the preoperative simulation phase identify the position of the inserts that are made to facilitate the passage of the blades during surgery. The blades chosen during the design phase have a thickness of $1.04 \mathrm{~mm}$; therefore, considering a tolerance margin, notches are made with a thickness of $1.08 \mathrm{~mm}$ (Figure 8 ).

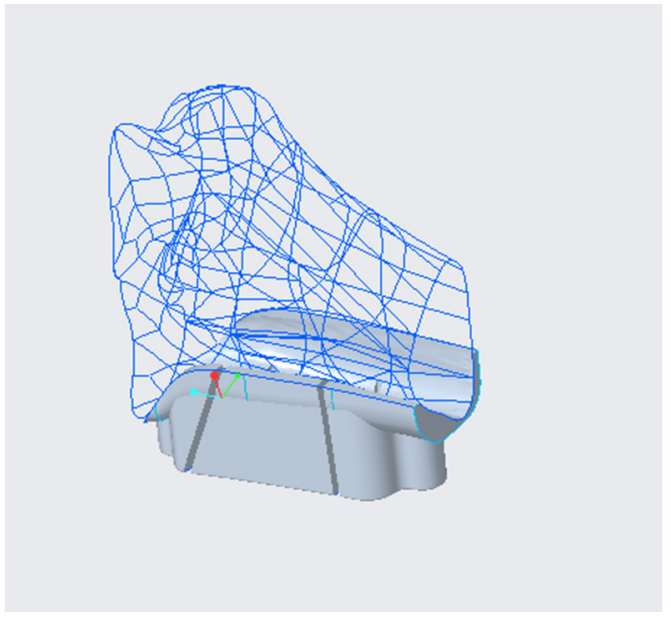

(a)

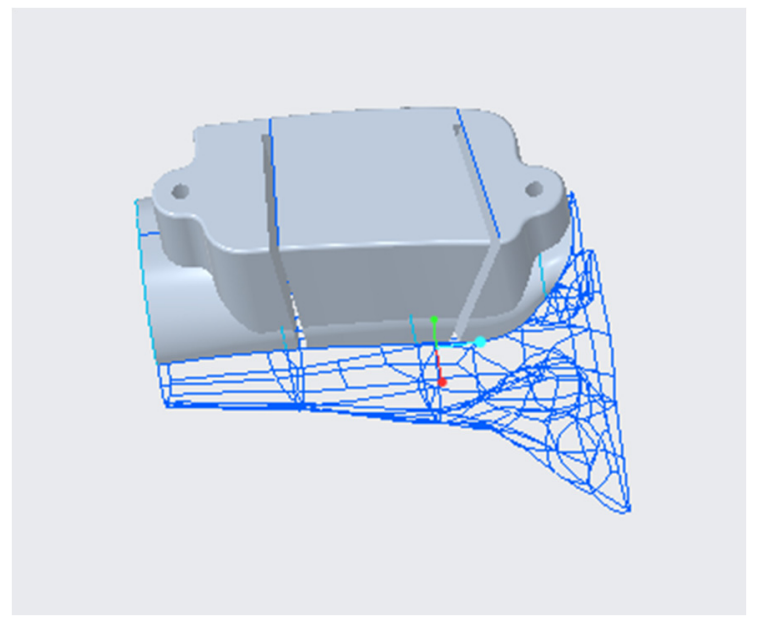

(b)

Figure 8. Design of the custom-made cutting guide performed on Creo Parametric: (a) from above; (b) from below.

\subsection{D Printing of the Surgical Guide}

The generated surgical guide template can be saved in Stl format. The Ultimaker Cura 4.8.0 slicer, made by Ultimaker B.V., Stationsplein 32, 3511 ED Utrecht, was used for printing the surgical guide. Cura is an open-source program developed by Ultimaker that converts a 3D model into instructions that the printer uses to produce the object. The printer chosen is the Delta-type EZT3D, a 3D printer that uses fused deposition modeling (FDM) technology as a printing system. Since the surgical guide is intended for use in the operating room, it must be sterilized before being used. An autoclavable material called HTPLA (High-Temperature PLA) was therefore chosen as the printing material (Figure 9). Table 2 indicates the printing parameters to be used for the HTPLA surgical guide.

Table 2. HTPLA Print Parameters.

\begin{tabular}{cc}
\hline PARAMETERS & VALUES \\
\hline Nozzle Temperature $\left[{ }^{\circ} \mathrm{C}\right]$ & 210 \\
\hline Heated Bed Temperature $\left[{ }^{\circ} \mathrm{C}\right]$ & 60 \\
\hline Print Speed $[\mathrm{mm} / \mathrm{s}]$ & $25-45$ \\
\hline Extrusion Width $[\mathrm{mm}]$ & $0.5 \mathrm{~mm}$ larger than the size of the nozzle \\
\hline Volume Flow $\left[\mathrm{mm}^{3} / \mathrm{s}\right]$ & $2-3$ \\
\hline
\end{tabular}




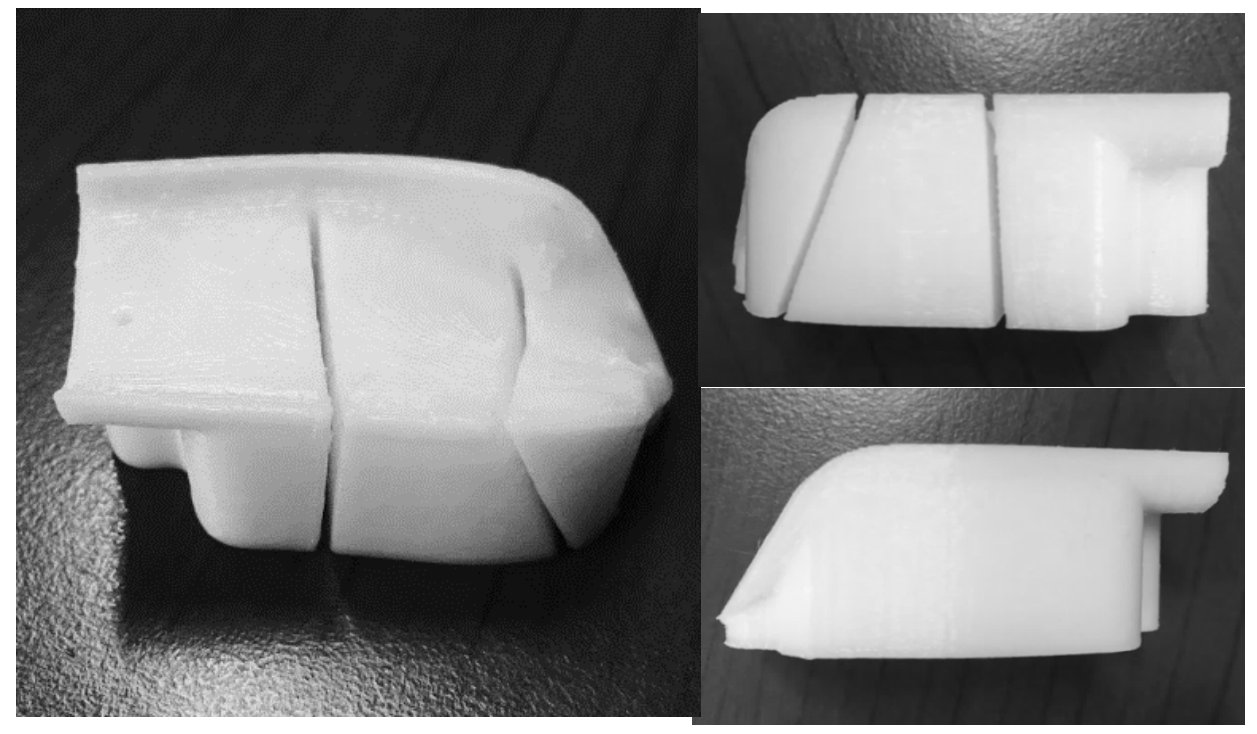

Figure 9. Printing the surgical guide in HTPLA from different angles.

\section{Results and Discussion}

The methodology described has led to the creation of a surgical guide that adapts perfectly to the patient's bone model. This favors its positioning in the operative phase and guarantees a precise cut of the bone that takes place exactly along the predetermined planes during the simulation (Figure 10).

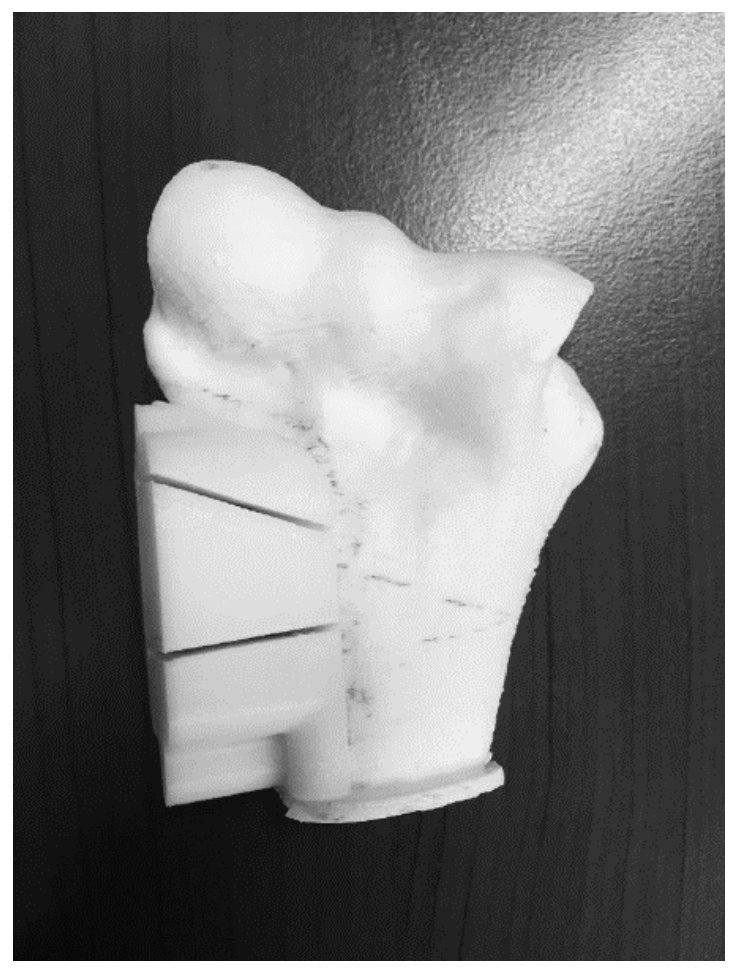

(a)

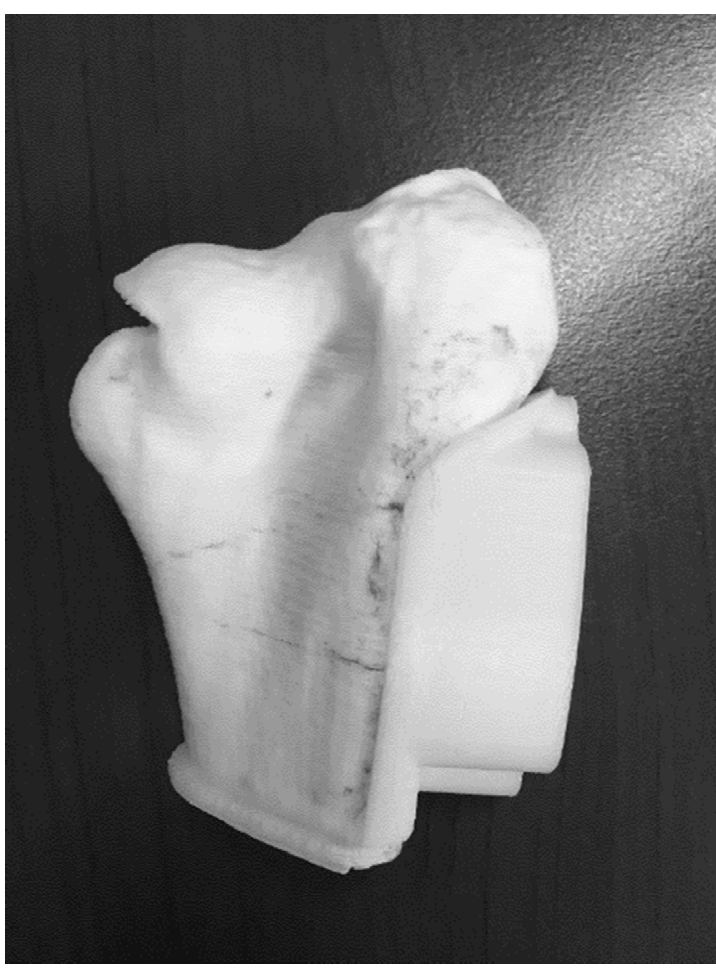

(b)

Figure 10. Perfect adhesion between the surgical guide and the bone model: (a) this favors its positioning in the operative phase and guarantees a precise cut of the bone that $(\mathbf{b})$ takes place exactly along the predetermined planes during the simulation. 
The analysis of the direct costs incurred to produce the surgical guide concerned:

- the cost of materials;

- $\quad$ the purchase of the 3D printer;

- $\quad$ the cost of the software used;

- the cost of qualified personnel.

A crucial point of the whole study was to find a material for printing that was biocompatible and non-toxic, with high mechanical properties, printable with FDM technology and sterilizable in an autoclave.

The choice fell on HTPLA. It is a material produced by the Proto-Pasta company and is obtained from heat-treated PLA. Like PLA, HTPLA is biocompatible, non-toxic and can be printed using the FDM technique.

In addition, HTPLA has a higher strength and tensile modulus due to its semicrystalline structure. The percentage of crystallinity in HTPLA can be improved by heat treatment to improve its mechanical properties.

Figure 11 compares the thermal and mechanical properties of PLA with those of HTPLA. In particular, the maximum tensile strength and modulus for the PLA samples are respectively $65.75 \mathrm{MPa}$ and $4.9 \mathrm{GPa}$ at $250{ }^{\circ} \mathrm{C}$. For the HTPLA samples, the maximum tensile strength and modulus were acquired respectively $67.4 \mathrm{MPa}$ and $5.65 \mathrm{GPa}$ at $250{ }^{\circ} \mathrm{C}$. This increase in tensile strength and modulus is due to the heat treatment and recrystallization of the samples, which improved the mechanical properties $[45,46]$.

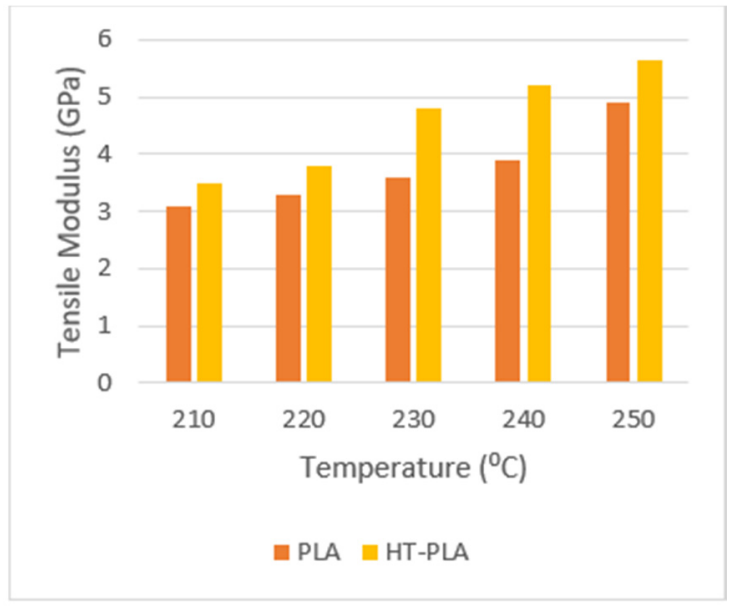

(a)

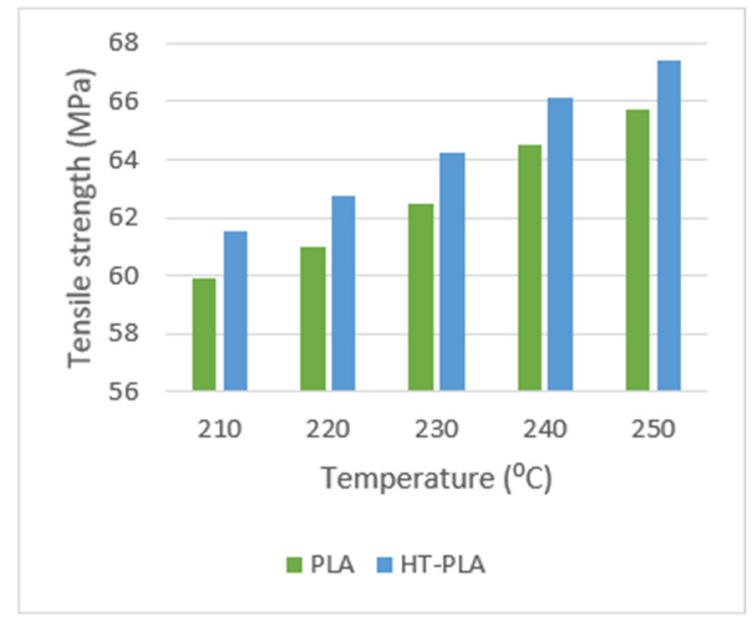

(b)

Figure 11. Tensile modulus values (a) and tensile strength values; (b) in terms of printing temperature.

The model printed in HTPLA requires a complete annealing. The cooking phase takes place in a laboratory oven. The $3 \mathrm{D}$ printed model is heated for $30 \mathrm{~min}$ at $115{ }^{\circ} \mathrm{C}$ and remains at this temperature for one hour. Finally, it is left to cool for $30 \mathrm{~min}$. After annealing, the HTPLA model can withstand up to $140{ }^{\circ} \mathrm{C}$.

Due to the ability of HTPLA to withstand higher temperatures, sterilization of the cutting guide in an autoclave is therefore possible.

The cost of HTPLA is approximately $68.00 \mathrm{EUR} / \mathrm{kg} .0 .01 \mathrm{~kg}$ of material is required to make the surgical guide.

The printer used in this study cost about 250 EUR and has a working life of approximately 2000 working hours.

Table 3 shows a comparison between this procedure and the more common ones present in the literature for the case of cubitus varus deformity. This comparison concerns the cost of materials and printers used. Entry level printers, easily available on the market, were taken as a reference. The cheapest printing technology is the FDM procedure. Specifically, the printer used in this study is a Delta-type EZT3D and costs around $€ 250$. The 
most expensive printing technology is the SLS procedure, with prices ranging between 7000 and 145,000 EUR for a single printer.

Table 3. Cost comparison.

\begin{tabular}{|c|c|c|c|}
\hline Printing Technique & Materials & Materials Cost (€/kg) & Printing Cost $(€)$ \\
\hline \multirow{4}{*}{ FDM } & ABS & 32.50 & \multirow{4}{*}{ from 150 to 800} \\
\hline & PLA & 37.30 & \\
\hline & HTPLA & 68.00 & \\
\hline & PETG & 45.30 & \\
\hline SLS & Nylon (PA12) & 85.70 & from 7000 to 145,000 \\
\hline SLA & Medical-grade resin & 429.99 & from 250 to 1000 \\
\hline $\begin{array}{c}\text { SLA/PoliJet } \\
\text { (Viper SLA Si2 3D System + Objet Eden 250) }\end{array}$ & Resin & 58.99 & $13,500+41,000$ \\
\hline
\end{tabular}

Cheaper materials include PLA, Acrylonitrile butadiene styrene (ABS) and Polyethylene Terephthalate Glycol-modified (PETG). However, these materials are not suitable for autoclaving, which is considered the safest method of sterilization. The most expensive material is medical resin. Raydent Surgical Guide (Zortrax) resin was also considered for cost analysis.

Ultimately, the use of the FDM procedure and the choice of HTPLA as the printing material is the best, both qualitatively and economically.

The innovative process described is in-house, so the cost of the location infrastructure has not been considered.

Mainly, free open-source software (Invesalius, made by Centro de Tecnologia da Informação Renato Archer (CTI), Brazil; MeshLab, made by Visual Computing Lab of CNR-ISTI, Italy; Meshmixer, made by Autodesk, Inc. 111 McInnis Parkway San Rafael, CA 94903. USA) were used. Table 4 shows a comparison between our procedure and the more common ones present in the literature in terms of procedure used, software, material used for printing, sterilization process and printer used. It should be noted that most of the procedures use commercial software (such as Mimics which is the most widely used software in the biomechanical field) or closed source software. Furthermore, the sterilization method used for prototypes is often not mentioned or specified.

Table 4. Procedure comparison.

\begin{tabular}{|c|c|c|c|c|c|}
\hline Ref. & Production & Informatic Procedure & Material & Sterilization & $\begin{array}{l}\text { 3D Printing } \\
\text { Technology }\end{array}$ \\
\hline $\begin{array}{c}\text { THIS } \\
\text { PROCEDURE }\end{array}$ & In-house & $\begin{array}{c}\text { Invesalius, MeshLab/Meshmixer, } \\
\text { PTC Creo }\end{array}$ & HTPLA & Autoclave & FDM \\
\hline $\begin{array}{l}\text { Zhang et al. } \\
2011[31]\end{array}$ & In-house & Materialise Mimics, Imageware & Acrylate Resin & $\begin{array}{l}\text { Sterilization is } \\
\text { not mentioned }\end{array}$ & SLA \\
\hline $\begin{array}{l}\text { Murase et al. } \\
2013 \text { [32] }\end{array}$ & $\begin{array}{l}\text { Nakashima } \\
\text { Medical }\end{array}$ & $\begin{array}{c}\text { Bone Simulator } \\
\text { (ORTHREE), Magics }\end{array}$ & Resin & $\begin{array}{l}\text { Sterilization is } \\
\text { not mentioned }\end{array}$ & SLA/PoliJet \\
\hline $\begin{array}{l}\text { Barbier et al. } \\
2019[36]\end{array}$ & In-house & Materialise Mimics & Nylon & $\begin{array}{l}\text { The sterilization method } \\
\text { used is not specified }\end{array}$ & SLS \\
\hline $\begin{array}{l}\text { Hu et al. } \\
2020[33]\end{array}$ & In-house & Materialise Mimics 17.0 & PLA & $\begin{array}{l}\text { Sterilization is } \\
\text { not mentioned }\end{array}$ & FDM \\
\hline
\end{tabular}

The estimated cost for a specialized operator is $20 \mathrm{EUR} / \mathrm{h}$. The design phase of the CAD surgical guide requires 20-30 h. of work depending on the complexity of the case treated, while the printing of the guide obtained takes about $3 \mathrm{~h}$. 
Ultimately, with all above considerations made, the cost of the surgical guide made is around 485 EUR.

\section{Proposed Improvements}

The present study must be seen in the light of some limitations. The cost analysis was performed on a single targeted case of surgical guide made for a patient with cubitus varus. A comparison was reported between the innovative methodology used and the alternative innovative procedures present in the literature. However, no comparison was offered between the costs of the innovative methodology and the traditional planning procedure.

A future development of the simulation could involve the consideration of soft tissues for the surgical guide. In this way, it will be possible for surgent faithfully reproduce the anatomy of the affected part including muscular and nervous structures of the patient. This would increase the accuracy and effectiveness of the entire process.

Another possible future development could involve a more accurate filling of the bone model in the molding phase so as to obtain also the real density of the bone.

\section{Conclusions}

This work shows an innovative procedure aimed at prototyping a custom-made surgical guide for a pediatric patient suffering from deformity of the cubitus varus.

A study on the most common innovative procedures found in the literature has shown that, to date, no material has been found that offers the right compromise between good mechanical properties and low cost. Therefore, HTPLA was chosen, a new and innovative material that offers a good combination of the existing ones and allows to obtain an easily sterilizable and resistant product.

To obtain a cost-effective surgical guide, an in-house procedure, free and open-source design software (except Creo Parametric) and an entry level 3D printer were chosen.

Ultimately, it is possible to consider the methodology described as a low-cost procedure that can be used in any healthcare institution and which improves the quality of care.

As demonstrated by $[31-33,36]$, the use of a customized surgical guide during surgery allowed to obtain an optimal cut of the bone wedge in a fully guided manner. In this way, the operations can be carried out straightforwardly even by less experienced surgeons, follow-on a lower risk for the patient.

Author Contributions: Conceptualization, L.F.; methodology, C.P.; software, A.L.; formal analysis, C.L.-C.; investigation, G.D., D.A., and G.M.S.; resources, G.L.D.G., G.T., D.A., P.Z., G.L.D.G., S.S., S.S.; data curation, C.P., P.P. and F.N.; writing — original draft preparation, C.P.; writing-review and editing, C.P. and C.L.-C.; supervision, L.F., G.D., A.L.; All authors have read and agreed to the published version of the manuscript.

Funding: This research received no external funding.

Institutional Review Board Statement: The study was conducted according to the guidelines of the Declaration of Helsini, and approved by the Ethics Committee of IOR Istituto Ortopedico Rizzoli (protocol “Parere definitivo allo studio prot. 3D-MALF-Responsabile Dr.ssa Elena Maredi-Codice CE AVEC 356/2018/Sper/IOR", code 0011181 and date of approval 1 October 2018).

Informed Consent Statement: Informed consent was obtained from all subjects involved in the study.

Data Availability Statement: Not applicable.

Conflicts of Interest: The authors declare no conflict of interest. 


\section{References}

1. Fini, M. Computer-Aided Surgery. ISTITUTO ORTOPEDICO RIZZOLI. (s.d.). Available online: http:/ / www.ior.it/laboratori/ lab-studi-precli-chirurg/computer-aided-surgery (accessed on 21 April 2021).

2. Frizziero, L.; Santi, G.M.; Liverani, A.; Napolitano, F.; Papaleo, P.; Maredi, E.; Gennaro, G.L.D.; Zarantonello, P.; Stallone, S.; Stilli, S.; et al. Computer-Aided Surgical Simulation for Correcting Complex Limb Deformities in Children. Appl. Sci. 2020, $10,5181$. [CrossRef]

3. Hafez, M. Custom-Made Cutting Guides for Total Knee Arthroplasty. Insall Scott Surg. Knee 2012, 1240-1254. [CrossRef]

4. Ballard, D.H.; Mills, P.; Duszak, R.; Weisman, J.A.; Rybicki, F.J.; Woodard, P.K. Medical 3D Printing Cost-Savings in Orthopedic and Maxillofacial Surgery: Cost Analysis of Operating Room Time Saved with 3D Printed Anatomic Models and Surgical Guides. Acad. Radiol. 2020, 27, 1103-1113. [CrossRef] [PubMed]

5. Zhang, Y.Z.; Chen, B.; Lu, S.; Yang, Y.; Zhao, J.M.; Liu, R.; Li, Y.B.; Pei, G.X. Preliminary application of computer-assisted patient-specific acetabular navigational template for total hip arthroplasty in adult single development dysplasia of the hip: Computer-assisted surgery planning navigation template hip. Int. J. Med. Robot. Comput. Assist. Surg. 2011, 7, 469-474. [CrossRef]

6. Hsu, A.R.; Davis, W.H.; Cohen, B.E.; Jones, C.P.; Ellington, J.K.; Anderson, R.B. Radiographic Outcomes of Preoperative CT Scan-Derived Patient-Specific Total Ankle Arthroplasty. Foot Ankle Int. 2015, 36, 1163-1169. [CrossRef]

7. Chareancholvanich, K.; Narkbunnam, R.; Pornrattanamaneewong, C. A prospective randomised controlled study of patientspecific cutting guides compared with conventional instrumentation in total knee replacement. Bone Jt. J. 2013, 95-B, 354-359. [CrossRef]

8. Abane, L.; Anract, P.; Boisgard, S.; Descamps, S.; Courpied, J.P.; Hamadouche, M. A comparison of patient-specific and conventional instrumentation for total knee arthroplasty. Bone Jt. J. 2015, 97-B, 56-63. [CrossRef]

9. Barrack, R.L.; Ruh, E.L.; Williams, B.M.; Ford, A.D.; Foreman, K.; Nunley, R.M. Patient specific cutting blocks are currently of no proven value. J. Bone Jt. Surg. Br. 2012, 94-B, 95-99. [CrossRef]

10. Barrett, W.; Hoeffel, D.; Dalury, D.; Mason, J.B.; Murphy, J.; Himden, S. In-Vivo Alignment Comparing Patient Specific Instrumentation with both Conventional and Computer Assisted Surgery (CAS) Instrumentation in Total Knee Arthroplasty. J. Arthroplast. 2014, 29, 343-347. [CrossRef] [PubMed]

11. Boonen, B.; Schotanus, M.G.M.; Kort, N.P. Preliminary experience with the patient-specific templating total knee arthroplasty. Acta Orthop. 2012, 83, 387-393. [CrossRef]

12. Boonen, B.; Schotanus, M.G.M.; Kerens, B.; van der Weegen, W.; van Drumpt, R.A.M.; Kort, N.P. Intra-operative results and radiological outcome of conventional and patient-specific surgery in total knee arthroplasty: A multicentre, randomised controlled trial. Knee Surgery, Sports Traumatology. Arthroscopy 2013, 21, 2206-2212. [CrossRef]

13. Ferdinando, F.; Antonio, C.; Nicola, M.; Santi, R.; Vincenzo, D.S.; Aaron, B.; Antonio, L.; Lorenzo, B. Implant Positioning in TKA Comparison Between Conventional and Patient-Specific Instrumentation. Orthopedics 2015, 38, e271-e280. [CrossRef]

14. Gan, Y.; Ding, J.; Xu, Y.; Hou, C. Accuracy and efficacy of osteotomy in total knee arthroplasty with patient-specific navigational template. Int. J. Clin. Exp. Med. 2015, 8, 12192-12201. [PubMed]

15. Hamilton, W.G.; Parks, N.L.; Saxena, A. Patient-Specific Instrumentation Does Not Shorten Surgical Time: A Prospective, Randomized Trial. J. Arthroplasty 2013, 28, 96-100. [CrossRef] [PubMed]

16. Kassab, S.; Pietrzak, W.S. Patient-specific positioning guides versus manual instrumentation for total knee arthroplasty: An intraoperative comparison. J. Surg. Orthop. Adv. 2014, 23, 140-146. [CrossRef] [PubMed]

17. Kerens, B.; Schotanus, M.G.M.; Boonen, B.; Kort, N.P. No radiographic difference between patient-specific guiding and conventional Oxford UKA surgery. Knee Surg. Sports Traumatol. Arthrosc. 2015, 23, 1324-1329. [CrossRef]

18. Nankivell, M.; West, G.; Pourgiezis, N. Operative efficiency and accuracy of patient-specific cutting guides in total knee replacement. ANZ J. Surg. 2015, 85, 452-455. [CrossRef]

19. Noble, J.W.; Moore, C.A.; Liu, N. The Value of Patient-Matched Instrumentation in Total Knee Arthroplasty. J. Arthroplasty 2012, 27, 153-155. [CrossRef]

20. Nunley, R.M.; Ellison, B.S.; Ruh, E.L.; Williams, B.M.; Foreman, K.; Ford, A.D.; Barrack, R.L. Are Patient-specific Cutting Blocks Cost-effective for Total Knee Arthroplasty? Clin. Orthop. Relat. Res. 2012, 470, 889-894. [CrossRef]

21. Pfitzner, T.; Abdel, M.P.; von Roth, P.; Perka, C.; Hommel, H. Small Improvements in Mechanical Axis Alignment Achieved with MRI versus CT-based Patient-specific Instruments in TKA: A Randomized Clinical Trial. Clin. Orthop. Relat. Res. 2014, 472, 2913-2922. [CrossRef]

22. Pietsch, M.; Djahani, O.; Zweiger, C.; Plattner, F.; Radl, R.; Tschauner, C.; Hofmann, S. Custom-fit minimally invasive total knee arthroplasty: Effect on blood loss and early clinical outcomes. Knee Surg. Sports Traumatol. Arthrosc. 2013, 21, 2234-2240. [CrossRef]

23. Rathod, P.A.; Deshmukh, A.J.; Cushner, F.D. Reducing Blood Loss in Bilateral Total Knee Arthroplasty with Patient-Specific Instrumentation. Orthop. Clin. N. Am. 2015, 46, 343-350. [CrossRef]

24. Renson, L.; Poilvache, P.; den Wyngaert, H.V. Improved alignment and operating room efficiency with patient-specific instrumentation for TKA. Knee 2014, 21, 1216-1220. [CrossRef] [PubMed]

25. Roh, Y.W.; Kim, T.W.; Lee, S.; Seong, S.C.; Lee, M.C. Is TKA Using Patient-specific Instruments Comparable to Conventional TKA? A Randomized Controlled Study of One System. Clin. Orthop. Relat. Res. 2013, 471, 3988-3995. [CrossRef] [PubMed] 
26. Yamamoto, I.; Ishii, S.; Usui, M.; Ogino, T.; Kaneda, K. Cubitus varus deformity following supracondylar fracture of the humerus. A method for measuring rotational deformity. Clin. Orthop. Relat. Res. 1985, 201, 179-185.

27. Jiang, H.; Li, M.; Wu, Y. Application of computer simulation in the treatment of traumatic cubitus varus deformity in children. Medicine 2019, 98, e13882. [CrossRef] [PubMed]

28. Murase, T.; Takeyasu, Y.; Oka, K.; Kataoka, T.; Tanaka, H.; Yoshikawa, H. Three-Dimensional Corrective Osteotomy for Cubitus Varus Deformity with Use of Custom-Made Surgical Guides. JBJS Essent. Surg. Tech. 2014, 4, e6. [CrossRef] [PubMed]

29. Omori, S.; Murase, T.; Oka, K.; Kawanishi, Y.; Oura, K.; Tanaka, H.; Yoshikawa, H. Postoperative accuracy analysis of threedimensional corrective osteotomy for cubitus varus deformity with a custom-made surgical guide based on computer simulation. J. Shoulder Elb. Surg. 2015, 24, 242-249. [CrossRef] [PubMed]

30. Tricot, M.; Duy, K.T.; Docquier, P.-L. 3D-corrective osteotomy using surgical guides for posttraumatic distal humeral deformity. Acta Orthop. Belg. 2012, 78, 538-542. [PubMed]

31. Zhang, Y.Z.; Lu, S.; Chen, B.; Zhao, J.M.; Liu, R.; Pei, G.X. Application of computer-aided design osteotomy template for treatment of cubitus varus deformity in teenagers: A pilot study. J. Shoulder Elb. Surg. 2011, 20, 51-56. [CrossRef] [PubMed]

32. Hu, X.; Zhong, M.; Lou, Y.; Xu, P.; Jiang, B.; Mao, F.; Chen, D.; Zheng, P. Clinical application of individualized 3D-printed navigation template to children with cubitus varus deformity. J. Orthop. Surg. Res. 2020, 15, 111. [CrossRef] [PubMed]

33. Maróti, P.; Kocsis, B.; Ferencz, A.; Nyitrai, M.; Lőrinczy, D. Differential thermal analysis of the antibacterial effect of PLA-based materials planned for 3D printing. J. Therm. Anal. Calorim. 2020, 139, 367-374. [CrossRef]

34. Aguado-Maestro, I.; De Frutos-Serna, M.; González-Nava, A.; Merino-De Santos, A.B.; García-Alonso, M. Are the common sterilization methods completely effective for our in-house 3D printed biomodels and surgical guides? Injury 2020. [CrossRef] [PubMed]

35. Barbier, N.; de Wouters, S.; Traore, S.; Duy, K.T.; Docquier, P.-L. Patient specific instrumentation for corrective osteotomy in case of posttraumatic cubitus varus in children. Acta Orthop. Belg. 2019, 85, 297-304. [PubMed]

36. Feng, L.; Wang, Y.; Wei, Q. PA12 Powder Recycled from SLS for FDM. Polymers 2019, 11, 727. [CrossRef]

37. Lindberg, A.; Alfthan, J.; Pettersson, H.; Flodberg, G.; Yang, L. Mechanical performance of polymer powder bed fused objects: FEM simulation and verification. Addit. Manuf. 2018, 24, 577-586. [CrossRef]

38. Zarringhalam, H.; Hopkinson, N.; Kamperman, N.F.; de Vlieger, J.J. Effects of processing on microstructure and properties of SLS Nylon 12. Mater. Sci. Eng. A 2006, 172-180. [CrossRef]

39. Osti, F.; Santi, G.M.; Neri, M.; Liverani, A.; Frizziero, L.; Stilli, S.; Maredi, E.; Zarantonello, P.; Gallone, G.; Stallone, S.; et al. CT conversion workflow for intraoperative usage of bony models: From DICOM data to 3D printed models. Appl. Sci. 2019, 9, 708. [CrossRef]

40. Frizziero, L.; Liverani, A.; Donnici, G.; Osti, F.; Neri, M.; Maredi, E.; Trisolino, G.; Stilli, S. New Methodology for Diagnosis of Orthopedic Diseases through Additive Manufacturing Models. Symmetry 2019, 11, 542. [CrossRef]

41. Caligiana, P.; Liverani, A.; Ceruti, A.; Santi, G.M.; Donnici, G.; Osti, F. An Interactive Real-Time Cutting Technique for 3D Models in Mixed Reality. Technologies 2020, 8, 23. [CrossRef]

42. Frizziero, L.; Santi, G.M.; Liverani, A.; Giuseppetti, V.; Trisolino, G.; Maredi, E.; Stilli, S. Paediatric Orthopaedic Surgery with 3D Printing: Improvements and Cost Reduction. Symmetry 2019, 11, 1317. [CrossRef]

43. Napolitano, F.; Frizziero, L.; Santi, G.M.; Donnici, G.; Liverani, A.; Papaleo, P.; Giuseppetti, V. Description of the CAD-AM Process for 3D Bone Printing: The Case Study of a Flat Foot. In Proceedings of the 5th NA International Conference on Industrial Engineering and Operations Management, Detroit, MI, USA, 10-14 August 2020; pp. 2248-2257.

44. Frizziero, L.; Donnici, G.; Liverani, A.; Santi, G.; Neri, M.; Papaleo, P.; Napolitano, F. Description of the CAD-AM Process for 3D Bone Printing: The Case Study of a Femur. In Proceedings of the 5th NA International Conference on Industrial Engineering and Operations Management, Detroit, MI, USA, 10-14 August 2020; pp. 2258-2266.

45. Akhoundi, B.; Nabipour, M.; Hajami, F.; Shakoori, D. An Experimental Study of Nozzle Temperature and Heat Treatment (Annealing) Effects on Mechanical Properties of High-Temperature Polylactic Acid in Fused Deposition Modeling. Polym. Eng. Sci. 2020, 60, 979-987. [CrossRef]

46. Chen, J.V.; Tanaka, K.S.; Dang, A.B.C.; Dang, A. Identifying a commercially-available 3D printing process that minimizes model distortion after annealing and autoclaving and the effect of steam sterilization on mechanical strength. 3D Print. Med. 2020, 6. [CrossRef] [PubMed] 